\title{
BIBECHANA
}

A Multidisciplinary Journal of Science, Technology and Mathematics

ISSN 2091-0762 (online)

Journal homepage: http://nepjol.info/index.php/BIBECHANA

\section{Compressibility and Moelwyn-Hughes Parameter of NaI crystals under high pressure, as the function of thermal properties}

\author{
Arun Kumar Khan \\ Department of Physics, R.M College, Saharsa, India \\ E-mail : arunkumarkhan@gmail.com \\ Article history: Received 8 October, 2012; Accepted 7 November, 2012
}

\begin{abstract}
The credit for the commencement of inter ionic potential function goes to Born and Lande, one of whose milestone has been their expression into inverse function. Similarly, Born and Mayer also proposed the exponential function of the potential for the repulsive component. However none of them could get the desired success. Subsequently, many more prominent scientists devoted their effort towards these thermal properties of the crystals, among which the endeavour of Jha and Thakur cannot be overlooked, who proposed a new interionic function to observe the properties of ionic crystal under high pressure. During its formulation they included both an inverse power function due to Born and Lande and an exponential function due to to Born and Mayer. Appreciably, Jha and Khan used it for studying the hyped thermal properties of NAI and CsI crystal under high pressure up to 100 Kilo bar.
\end{abstract}

Keywords: Moelwyn-Hughes parameter; Isothermal compressibility; NAI crystals; Debye temperature

\section{Introduction}

Solid state physics went through a roller coaster ride in the begining of the last century. Riding on the same momentum, Born model of ionic solids [1] provided a substantial method to calculate the elastic and thermal properties of ionic crystal under high pressure, whose calculations are based on an inter ionic potential function. Repulsive term being an important component of the potential function, has been described by Born and Lande by an inverse power function, whereas, the same has been described as an exponential function by Born and Mayer. In contrary, Roberts and Smith [2] found none of these functions to be successful, if the compression of Sodium Halide crystals are concerned.

\section{Formalism}

The new inter ionic potential function as proposed by Jha and Thakur [3] has included both an inverse power function due to Born and Lande and an exponential function due to Born and Mayer as it repulsive component. After which, Jha [4] used it for studying the thermal properties of NaI and CsI crystal under 
A. K. Khan / BIBECHANA 9 (2013) 88-91 : BMHSS, p. 89 (Online Publication: Nov., 2012)

high pressure. To our happiness, we disclose the thunderous success of this potential to describe the elastic properties of $\mathrm{NaI}$ crystals under high pressure up to $100 \mathrm{Kbar}$.

Using reduced units of equilibrium inter ionic distance $\mathrm{R} 0$ for distance and e2/R0 for energy, the new interionic potential for the crystal under study can be written as [3]

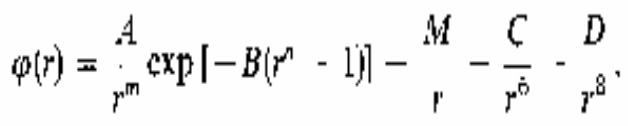

Where $\mathrm{r}$ is the inter ionic distance, $\mathrm{A}, \mathrm{B}, \mathrm{m} \& \mathrm{n}$ are the potential parameters which are constants for a given cnrystal , M is the Madelung constant , C \& D are van der Walls costants for dipole-dipole and dipole-quadruple interactions, respectively and e is the electronic charge.Crystal properties have also been calculated using Born-Lande' and Born Mayer potential for the sake of comparison. These can be written as:

$$
\text { (i) }-\frac{A_{1}}{r^{m i}}-\frac{M}{r}-\frac{C}{r^{6}}-\frac{D}{r^{B}}
$$

and

$$
\varphi(r)=A_{2} \exp \left(-\frac{r}{\theta}\right)-\frac{M}{r} \quad \frac{C}{r^{6}} \cdot \frac{D}{r^{h}} .
$$

\section{Results and Discussion}

Jha and Thakur [3] have described a procedure, using which the parameters of the new potential have been calculated. $m$ obtains only integral values, whereas $n$ has been varied in steps of 0.1 . The data for input crystal has been taken from Tosi [1] and Ashcroft and Mermin [5]. Potential parameters of the Born - Mayer potentials have been calculated in the usual manner. Values of potential parameters for the

\begin{tabular}{|c|c|c|c|}
\hline Parameter & Value & Parameter & Value \\
\hline $\mathrm{C}$ & 0.0595 & \multicolumn{2}{|c|}{ Born - Lande' potential } \\
\hline $\mathrm{D}$ & 0.0075 & $m_{1}$ & 8.3678 \\
\hline \multicolumn{2}{|c|}{ New potential } & $A_{1}$ & 0.25868 \\
\hline $\mathrm{m}$ & 4 & \multicolumn{2}{|c|}{ Born - Mayer potential } \\
\hline $\mathrm{n}$ & 2.9 & $1 / \square \square$ & 9.3678 \\
\hline A & 0.213852 & $A_{7}$ & 2704.6774 \\
\hline $\mathrm{B}$ & 2.110957 & & \\
\hline
\end{tabular}
crystal under study have been listed in Table 1.

Table 1: Potential parameters of NaI crystals in reduced (dimensionless) units

At a given compression, the pressure has been calculated with the help of Debye's equation of state [6],

$$
\mathrm{P}=-(ð \mathrm{Eo} / \delta \mathrm{V})+\gamma \mathrm{ED} / \mathrm{V}
$$

Here $E_{o}$ is the internal energy of the volume, $P$ pressure at 0 Kelvin, $E_{D}$ the Debye energy of the crystalat the temperature at which the crystal properties are being studied, and $\gamma$ the Gruneisen parameter. Here we 
have taken in to account the variation of $E_{D}$ and $\gamma$ with pressure, but their temperature has been ignored. $\mathrm{E}_{\mathrm{D}}$ has been calculated by calculating the Debye temperature. Jha and Thakur[3] explained the calculation

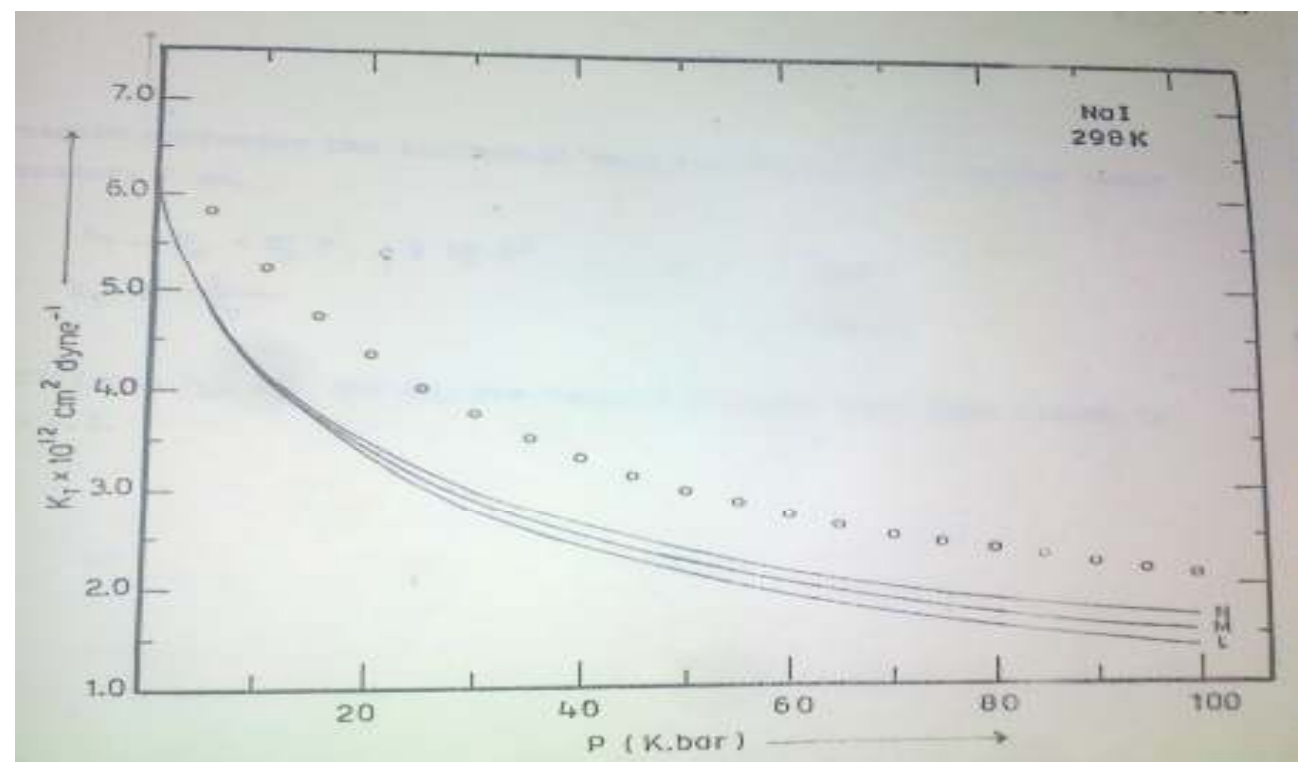

Fig. 1. Variation of isothermal compressibility with pressure

of Gruneisen parameter and Debye temperature.

The isothermal compressibility has been calculated with the relation

$$
\mathrm{K}_{\mathrm{T}}=-1 / \mathrm{V}(ð \mathrm{~V} / ð \mathrm{p})_{\mathrm{T}}
$$

The Moelwyn-Hughes parameters[7,8] is the pressure derivative of the isothermal Bulk modelus BT. It is defined by

$$
\mathrm{C}_{1}=\left({ }_{\mathrm{T}} / ð \mathrm{P}\right)_{\mathrm{T}}
$$

The computed results have been displayed in fig. 1 and 2. Fig. 1 shows the variation of KT with pressure at room temperature $(298 \mathrm{~K})$. Fig. 2 shows the variation of $\mathrm{C} 1$ with pressure at room temperature. Curves marked L have been drawn using the Born-Lande' potential, curves marked M using the Born-Mayer Potential and curves marked $\mathrm{N}$ using the new potential. The open circles are estimates of KT and C1 obtained from the compression data of Bridgman [9] using a modified Murnaghan equation [10, 11]. This equation helps us to express BT as a parabolic function of $\mathrm{P}$,

$$
\mathrm{BT}=\mathrm{B}_{0}+\mathrm{B}_{1} \mathrm{P}+1 / 2 \mathrm{~B}_{2} \mathrm{P}^{2}
$$

It follows from the definition of the Moelwyn-Hughes parameter that

$$
\mathrm{C}_{1}=\mathrm{B}_{1}+\mathrm{B}_{2} \mathrm{P}
$$

Values of $\mathrm{B}_{0}, \mathrm{~B}_{1} \& \mathrm{~B}_{2}$ have been mentioned in figure 1 . 
A. K. Khan / BIBECHANA 9 (2013) 88-91 : BMHSS, p.91 (Online Publication: Nov., 2012)

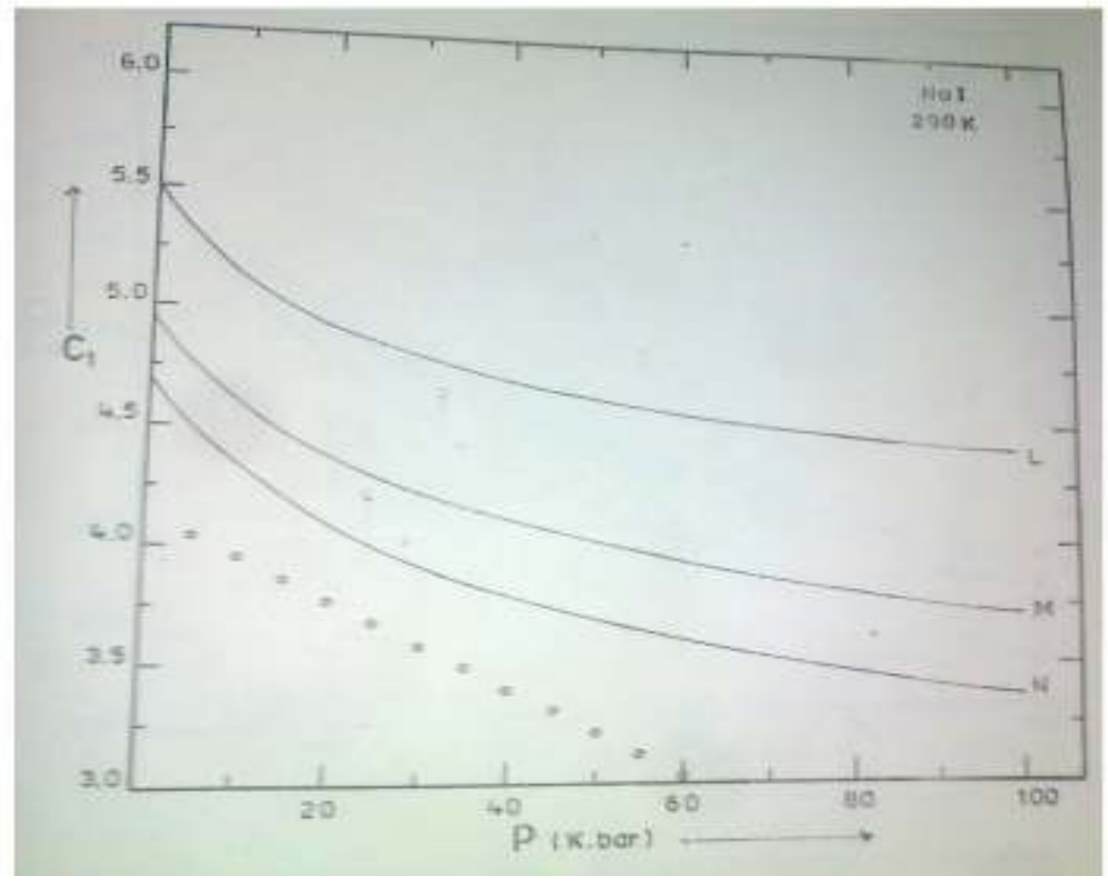

Fig. 2. Variation of Moelwyn-Hughes parameter with pressure

\section{Conclusion}

However, the observation cannot be overlooked that the inverse power law of Born Lande' is not apposite for predicting the elastic properties of $\mathrm{NaI}$ crystal under high pressure, whereas the exponential laws is better for studying the elastic properties of crystal under high pressure. The new potential is most successful in explaining mechanical and thermal properties of $\mathrm{NaI}$ crystal under high pressure i.e, from 100 kilo bar study.

\section{References}

[1] M.P. Tos, Solid State Physics, Ed. F. Seitz and D. Turnbull, Academic Press, 16 (1964) 1.

[2] R. W. Roberts and C. S. Smith, J. Phys. Chem. Solids, 31(1970) 619.

[3] B. N. Jha and K. P. Thakur, Physics, 173B (1991) 408.

[4] B. N. Jha, Physica, 192B (1993) 253.

[5] N. W. Ashcroft and N. D. Mermin, Solid State Physics, Holt, Rinehart and Winston, New York (1976) 459.

[6] C. Kittel, Introduction to Solid State Physics, John Wiley and Sons, Inc., New York (1996) 182.

[7] K. P. Thakur, Acta Cryst., A32 (1976) 363.

[8] K. P. Thakur, Physics of the Earth and Planetary Interiors, 27 (1982) 235.

[9] P. W. Bridgman, Proc. Amer. Acad. Arts Sci., 76 (1945) 1.

[10] F. D. Murnaghan, Proc. Nat. Acad. Sci. USA, 30 (1944) 244.

[11] F. D. Murnaghan, Finite Deformation of an Elastic solid, John Wiley and Sons, Inc., New York (1951). Further Readings

[12] Zhang Hong Tangjin and Cheng Xin-Lu, Chinese Physics Letters (2008).

[13] Ayu.. Kuznetsov, L. Dubrovimin Sky, A Kurnosov, M. M. Lucchese, W. Crichton and C.A. Achete, Advances in Physical Chemistry, (2009)Article ID 180784.

[14] Alapana Tiwari, N. K. Gaur and P Singh, Journal of Physics (2010).

[15] A.K. Khan, BIBECHANA, 7 (2011) 49. 